\title{
BIOGRAFIA, MEMÓRIAS COLONIAIS \\ E LEGADOS PÓS-COLONIAIS
}

\author{
Margarida Paredes ${ }^{1}$
}

RESUMO: Este texto tem como objetivo cruzar a História de Vida da autora, na múltipla condição de guerrilheira, escritora e antropóloga com a teoria Pós-colonial e Feminista. Espetadora privilegiada do fim do Império português, a autora participou na Luta de Libertação anticolonial do MPLA. Mais tarde regressou a África através da escrita romanesca e da pesquisa científica com guerrilheiras na Luta Armada em Angola.

PALAVRAS-CHAVE: África; Angola; Guerrilheira; Feminismo; Pós-colonialismo.

ABSTRACT: This text intends to cross the author's Life Story, in the multiple condition of freedom fighter, writer and anthropologist with the Postcolonial and Feminist theory. The author was a privileged spectator of the end of the Portuguese Empire and participated in the MPLA Liberation Struggle. A few years later, she returned to Africa through Romanesque 
writing and scientific research with guerrillas women in the Armed Struggle in Angola.

KEYWORDS: Africa; Angola; Freedom Fighter; Feminism; Postcolonialism. 


\section{INTRODUÇÃO}

Este texto foi escrito na múltipla condição de ex-guerrilheira, escritora e antropóloga e com uma intencionalidade muito precisa, ou seja, cruzar a História de Vida da autora com a teoria pós-colonial e feminista. A proposta não é fácil para quem, como eu, vem de uma cultura ligada à ocupação e opressão colonial em África e no Brasil. Venho de um país com responsabilidades históricas no tráfico de escravos, uma das maiores feridas da humanidade. Com esta afirmação acabo de definir o meu lugar de enunciação, vou falar do outro lado do Atlântico, do país onde nasci, Portugal. O mesmo Portugal que explorou açúcar, ouro, diamantes, café, índios, escravos e por isso não morreu, o Portugal que vive na persistência da colonialidade herdada do Império. Mas se escolho o Norte e a velha e melancólica cidade de Coimbra onde nasci para me situar conceptualmente, não escolho, como lugar único de pertencimento, os limites de Portugal. O espaço que reivindico para me situar como pessoa neste mundo expandido é muito mais amplo.

Tenho uma história de vida construída entre a Europa e África, atravessei muitas paisagens e dialoguei com muitas culturas. Paul Gilroy ao questionar a noção de identidade diz que o conceito de diáspora no espaço do Atlântico "oferece uma alternativa imediata à disciplina severa do parentesco primordial e do pertencimento enraizado" $(2007,151)$. Gilroy que me perdoe se estou a embranquecer o seu Atlântico Negro, mas eu também pertenço a este mundo diaspórico. Um mundo onde, como Frantz Fanon escreveu "Você chegou muito tarde, tarde demais, haverá sempre um mundo - um mundo branco - entre vocês e nós" (apud BHABHA, 1998, 327). 
Costumo dizer, com alguma ironia, que em criança fui colonialista porque a branquidade me permitiu viver uma infância dourada em territórios africanos ocupados por Portugal. Lembro-me de cruzar os Oceanos Atlântico e Índico com a minha família em viagens de sonho, hospedada em luxuosos camarotes de deslumbrantes paquetes transatlânticos. O mau pai, oceanógrafo, era pesquisador do Instituto de Investigação Científica de Angola, o meu tio Mário, um empresário, foi proprietário do primeiro avião particular da ex-colónia, o meu sogro, com uma origem de classe diferente era conhecido em Luanda pelo Rei do Carvão. Esta genealogia ou "disparate do acaso", para referir Foucault, (FOUCAULT, $2007,18)$ permitiu que algumas das minhas memórias sejam muito felizes, mesmo se não são inocentes.

$\mathrm{Na}$ era colonial o brilho do Império era diminuído pelas ações dos "terroristas", "selvagens" ou "negralhada", como a comunidade branca em Angola se referia aos africanos. Eu sei quanto é doloroso ouvir a palavra "negralhada", termo que representa a história da opressão colonial e que remete para uma velha e esquizofrénica cultura de águas muito turvas, uma cultura histórica de humilhação e inferiorização dos africanos, a cultura colonial. Mas não estou a referir-me a uma realidade assim tão distante porque ainda a vivi até à idade adulta em África e, hoje em dia, o racismo e a colonialidade do terror racial estão cada vez mais presentes em muitas das sociedades contemporâneas.

$\mathrm{Na}$ adolescência, numa altura em que já não me sentia a dona do Império nem do mundo, fui testemunha de alguns acontecimentos violentos em Angola que abalaram a minha segurança e contrariam a versão do colonialismo português ter sido "brando", como tem sido propagado pela "cartilha colonial". Quando percebi que vivia numa realidade social 
suja que hierarquizava a humanidade racialmente, abriu-seme um corredor transcultural que me permitiu rejeitar os estereótipos nos quais a comunidade branca de Angola vivia mergulhada e aferir o mundo de outra maneira.

Apesar da Guerra Colonial que asfixiava o país, nos anos $60 / 70$, os ventos da revolução cultural europeia, a minissaia, a pílula anticoncecional, Maio de 68, os Rolling Stones, a Luta de Classes, os livros de Fanon e o movimento da Negritude também chegavam às ex-colónias. Os livros proibidos compravam-se clandestinamente nas livrarias e o ruído da longa Luta de Libertação, ali no mato, tão perto, era ouvido nas cidades. À noite eu e os meus amigos não perdíamos a emissão do programa de rádio do MPLA, "Angola Combatente", programa emitido de Brazzaville e proibido pela polícia política, a PIDE, e sonhávamos com utopias poderosas, como a liberdade e a independência. Por razões de solidariedade com os africanos e romantismo revolucionário, em 1973 aderi, aos 19 anos, a um dos movimentos de libertação de Angola, o MPLA. A Guerra Colonial foi uma ferida da qual não fui cúmplice. Como me construi como uma jovem mulher insubmissa e avessa à disciplina foi na Luta de Libertação que encontrei espaço para viver a minha rebeldia. Neste período em que pertenci à família dos velhos camaradas do MPLA, tive o privilégio de conviver com pessoas muito especiais que aceitavam com carinho o meu inconformismo. Recordo com saudade a Ruth Lara, o poeta António Jacinto, e os Cmdts Valódia e Dangereux, entre muitos outros, para referir apenas amigos que faleceram.

Embora defenda que a Luta de Libertação e a violência naquele contexto faziam sentido, como Fanon ensinou ao considerar a Luta de Libertação um meio importante através do qual o colonizado recuperava a sua agência e dignidade, "A 
violência é uma força purificadora que liberta o colonizado dos complexos de inferioridade, do seu desespero e inação, fá-lo destemido e restaura o seu amor-próprio." (FANON, 1968, 94, tradução nossa), não tenho um discurso nostálgico em relação à luta armada, porque não foi uma aventura romântica, mas um recorte histórico violento, num mundo dividido, povoado de medos intangíveis, mortes escusadas e exclusões várias. Aproveitei esses momentos que vivi contra a corrente para criar laços baseados numa experiência e solidariedade comum, portanto para criar ou imaginar uma identidade compartilhada e vinculada a Angola. Seis anos depois da Independência voltei a partir no rescaldo da revolta fratricida do 27 de Maio de 1977 no MPLA, que opôs Nitistas a Netistas. A repressão que se lhe seguiu matou milhares de jovens e bombardeou todos os meus sonhos e esperanças. Porque os sentimentos contam, ficaram os amigos e os afetos.

Regressei a Angola através da escrita com um pequeno romance pós-colonial que foi editado em 2006, "O Tibete de África", e que se inscreve no espaço das narrativas que percorrem vários países e diferentes culturas. Este livro veio a revelar-se ser o primeiro romance sobre os denominados "retornados" das ex-colónias, ou seja, sobre o êxodo da comunidade branca de Angola para Portugal em 1975. Mais recentemente, o livro de Isabela Figueiredo, "Caderno de Memórias Coloniais" (2015) ou o livro de Dulce Maria Cardoso, "O Retorno" (2011), deram continuidade a uma temática que iniciei com essa obra, ou seja, o processo de descolonização, do ponto de vista da literatura. Foi a romancista, jornalista e académica Raquel Ribeiro (2015) que notou que, enquanto os homens escrevem sobre a guerra colonial, as mulheres escrevem sobre a descolonização, estando as escritoras mais 
viradas para processos de transformação histórica e social do que para as feridas da guerra. Também foi o primeiro livro da literatura portuguesa a narrar uma relação sentimental interracial, entre uma mulher branca e um homem negro, numa base de igualdade social, dado que os protagonistas são os dois engenheiros numa grande empresa de telecomunicações.

Na sequência desse romance, o título deste texto, "Biografia, Memórias Coloniais e Legados Pós-coloniais", ancorado no entrelugares de Homi Bhabha (1998), é um pretexto para pensar este conceito como "um espaço de intervenção que permite a gestação e conceptualização de novos significados", cito Anzaldúa (1988) à qual acrescento que a produção de novos significados se faz através da teoria "abrindo espaços intermédios (in-between spaces) ou interstícios nos quais o sujeito se posiciona [mesmo] provisoriamente" (COSTA, 2002). Portanto vou tentar incorporar a "arma da teoria", nas palavras de Amílcar Cabral (2008), ao discurso da experiência vivida, sem a naturalizar, e assim pensar os legados póscoloniais. O meu olhar vai ser derramado sobre um locus decorrente da guerra em Angola.

Desde que escrevi "O Tibete de África" (2006) e assumi que participei na Luta de Libertação em Angola, ao lado do MPLA, tenho sido confrontada em Portugal com acusações violentas de traidora à pátria por parte dos ultranacionalistas e antigos combatentes das Forças Armadas Portuguesas, que não sabem lidar com o passado colonial, não compreendem as versões da História, as suas contradições e complexidades. No entanto, o meu lugar neste confronto de memórias não é conflituante porque, ao contrário dos militares que combateram na Guerra Colonial, nunca duvidei que, na Luta de Libertação, estava do lado certo da História. No dia em que acabou a soberania portuguesa em África, 11 de Novembro de 1975, achava-me 
na praça onde foi proclamada a independência de Angola e participei no ritual simbólico de passagem do fim da ordem colonial para a Angola independente e soberana. Tive o privilégio de ver nascer um país pelo qual lutei e de fechar a porta do Império.

Em 2010 regressei a Angola no âmbito do meu doutoramento em Antropologia para pesquisar as mulheres ex-combatentes. Angola estava finalmente em paz. O fim da guerra civil em 2 de Fevereiro de 2002 consagrou o MPLA no poder. A guerra não só confirmou a hegemonia do MPLA, como projetou Angola como uma potência regional, ao mesmo tempo que os baixos índices de desenvolvimento humano (IDH) a colocam entre os países onde a vida é mais incerta e difícil. O todo-poderoso regime de José Eduardo dos Santos, há 37 anos no poder, define os contornos de um estado autoritário e militarista, governado por uma elite social e política corrupta e nepotista, que trata os opositores não como adversários políticos, mas sim como "inimigos" e antipatriotas, persistindo o regime numa cultura de exclusão herdada da guerra civil. Citando um comentário recente de Agualusa, "Tantos anos após o fim da guerra, prossegue a tentativa de desnacionalização e de desumanização de todas as vozes independentes" (AGUALUSA, 2016). Do ponto de vista dos sujeitos, homens e mulheres, os angolanos acolheram de braços abertos as oportunidades da paz que estão a permitir que as pessoas reconvertam as suas trajetórias de vida, obrigando-as a gerir as memórias e um passado ligado à cruel experiência da guerra, reformulando os seus papéis e reposicionando-se como novos atores sociais.

Em relação às mulheres ex-combatentes, minhas companheiras de armas, quando comecei o trabalho de campo fui confrontada com o facto das antigas guerrilheiras 
do MPLA, assim como as mulheres-soldado das FAPLA ou as ex-combatentes da FNLA e da UNITA, todas se queixarem de terem sido esquecidas ou discriminadas, o que é motivo de grande revolta e sofrimento para estas mulheres. Independentemente de estarem no poder ou pertencerem às margens sociais, serem intelectuais, empresárias ou mães de família, pertencerem ao partido do poder ou à oposição, terem sido vencedoras ou vencidas, todas lamentam que a sua participação na luta anticolonial ou na guerra civil seja desvalorizada e o seu lugar na construção do estado angolano reduzido a um papel secundário. Mesmo quando o estado reconhece institucionalmente a sua participação, muitas delas queixam-se de silenciamento e do facto dos homens se estarem a apropriar da História e do protagonismo neste processo. Esta é a leitura que algumas combatentes, rompendo com continuidades essencialistas herdadas do tempo colonial, fazem da sua experiência. Experiência legitimada por Staya Mohanty (1993) na sua obra Literary Theory and the Claims of History, ao demonstrar que o princípio epistémico da prática legitima experiências pessoais e identidades construídas política e culturalmente na luta.

Ao ser confrontada com as memórias e testemunhos de antigas guerrilheiras entendi que a perceção subjetiva que tinha da participação das mulheres nas Lutas de Libertação e nas guerras não eram questões decorrentes de preconceitos ou perspetivas históricas diferentes e sim discursos de lógicas dominantes, de relações de poder, estratégias de exclusão e marginalização das mulheres. Eram resultado de uma hegemonia da cultura patriarcal. Como considero problemática a vitimização e James Baldwin (1985) diz-nos que é impossível falar do ponto de vista da vítima, ou seja, a partir desse lugar de inferiorização que os "outros" concebem 
para colocar as mulheres nas guerras não percecionando o sujeito através das suas ações e da singularidade das suas práticas sociais (PAREDES, 2015), interroguei-me, no início da pesquisa, como seria possível trabalhar a participação das mulheres dentro de uma lógica diferente que rompesse com as representações e estereótipos que nos remetem para a imagem monolítica que as inscreve no inferior ou no exótico (FEMENÍAS, 2006).

Por causa da particularidade de ser portuguesa e ter lutado por Angola, tenho estado sempre com um pé dentro e outro fora das realidades que vivi. O deslocamento provocado por este vaivém entre experiência e empírea levou-me a fazer uma releitura da história das ex-combatentes angolanas e da sua participação nas lutas de descolonização e nas guerras civis numa ótica feminista e emancipatória debruçada sobre a construção da identidade e das relações políticas e sociais de género. Um olhar derramado sobre a positividade e agenciamento da participação das combatentes, mesmo se, em situações limite, as suas opções se traduziram em passamento e vitimização. Para a teórica brasileira, Cláudia de Lima Costa, "a força do feminismo deve-se ao facto de construir positividades para os seus sujeitos com base na materialidade das experiências que as mulheres têm do social" (2002). De facto esta participação das mulheres combatentes não foi apenas um ato de resistência ao colonialismo e um ato de fraternidade no contexto dos discursos nacionalistas, mas um ato de cultura e libertação, como nos ensinou Amílcar Cabral (2008, p. 228-231). Este envolvimento deve ser considerado feminista no continente africano e, sobretudo, coloca as mulheres no centro dos discursos da modernidade, numa altura em que a experiência da modernidade em África, para as mulheres, está sempre a ser questionada. 
As africanas como mulheres e colonizadas estavam enredadas numa dupla marginalidade, como mulheres e como colonizadas. Essa dupla condição de marginalidade levou-as a explorar novas formas de luta e solidariedades. O envolvimento nas lutas de libertação não tem sido olhado como uma luta feminista, porque os movimentos de libertação subordinavam a emancipação das mulheres à prioridade da libertação nacional e, elas próprias, as mulheres que lutaram nas guerras anticoloniais, nos anos sessenta e setenta, não se identificavam como feministas e muitas ainda hoje não se identificam. À primeira vista parece que não houve, na época, um diálogo entre estas mulheres e as teorias feministas mundiais ou com as redes feministas transnacionais, mas, de uma maneira ou de outra, as ideias viajavam, atravessavam os vários continentes e as mulheres africanas estavam no terreno de luta, tinham ideias de resistência e práticas feministas. A guerrilheira Deolinda Rodrigues, ao refletir sobre "O papel da Mulher na Luta Armada", escreveu em 1965:

A mulher sendo uma parte essencial do povo, está em primeiro lugar na discriminação. [...] As mulheres pretas em todo o mundo compreendem bem esta verdade porque elas são discriminadas duas vezes: por serem mulheres e por causa da cor da pele [...] Hoje nós as angolanas sabemos que há muito trabalho que nós podemos fazer para avançar a nossa luta, [...] até o fazer parte das milícias nas sanzalas e pegar em armas para lutar contra os portugueses no maquis (Arquivo Lúcio Lara, Associação Tchiweka).

Deolinda Rodrigues esteve exilada nos Estados Unidos e, no ano de 1959, correspondeu-se com Martin Luther King, o que indica que tinha conhecimento da luta do movimento 
pelos direitos civis dos negros nos EUA e provavelmente do movimento das mulheres negras. Este texto, ao enunciar uma dupla discriminação, de género e racial, configura um "feminismo negro" que Deolinda deve ter bebido nos Estados Unidos e as suas reflexões revelam uma consciência feminista e apontam para um feminismo africano avant la lettre.

Segundo Ella Shohat (2004) "o ativismo por si só pode ser visto como uma forma de teorização, um teste prático de ideias e [...] muitas [mulheres] subestimam a sua própria contribuição histórica...". Muitas das mulheres que entrevistei, hoje vinculadas a um ativismo social e político, cada vez menos desconfiam "da incorporação da teoria como instrumento de formação e de luta intelectual para as mulheres" (RICHARD, 2002). É evidente que já não é possível, por exemplo, pensar no papel das ex-combatentes sem entrar em diálogo com a mais recente produção da teoria feminista. Sobre os problemas de tradução cultural, Cláudia de Lima Costa diz que "cabe à crítica feminista examinar com atenção o processo de tradução cultural das teorias e dos conceitos feministas de modo a desenvolver uma certa habilidade geopolítica ou transnacional de ler e escrever" (2002).

No sentido de resgatar o papel histórico e a memória da participação destas mulheres nas lutas de libertação, nos conflitos pós-coloniais e na construção dos novos estadosnação, mesmo daqueles que estão a ser construídos sob o signo de exclusões múltiplas, como é o caso de Angola, criei um arquivo de memórias de guerra no feminino porque estes testemunhos não só permitem salvar o dito para as gerações futuras, como permitem descentrar do ocidente as grandes narrativas e assim "revelar as operações do imperialismo 406 
conceitual, intelectual [...] mais notadamente nas formas de colonialismo e racismo" segundo Alice Jardine (apud COSTA, 2004).

O feminismo em África será uma das contribuições possíveis para pensar o continente nestes tempos pósmodernos e pós-coloniais. A literatura mergulhando na experiência autobiográfica também tem um papel a desempenhar, dando visibilidade a questões históricas, sociais e culturais das mulheres como sujeitos modernos, em constantes deslocamentos na contemporaneidade $\mathrm{e}$ resistindo a discursos homogeneizantes. A força da memória permite a construção de poéticas e políticas que reinventem o presente.

Os depoimentos de mulheres angolanas que combateram na Luta Armada, ao narrativizarem as suas vidas e experiências de guerra, ao mesmo tempo que criam para si próprias novas formas de vida, produzem também novos significados, novos simbolismos, criam um espaço de representação no imaginário nacional e de intervenção na nova realidade angolana semelhante à produção de sentidos que ocorre na literatura.

\section{NOTA}

${ }^{1}$ Doutora em Antropologia pelo Instituto Universitário de Lisboa (ISCTEIUL). Pesquisadora/professora convidada da Universidade Federal da Bahia (UFBA), no Programa de Pós-graduação em Antropologia (PPGA). E-mail: margarida_paredes@yahoo.com. 


\section{REFERÊNCIAS}

AGUALUSA, J. E., in Rede Angola, Não há pior surdo do que aquele que não quer ouvir, http://www.redeangola.info/opiniao/ nao-ha-pior-surdo-do-que-o-que-nao-quer-ouvir/, consultado em 28/11/2016, 18:14.

ANZALDÚA, G., Boderlands/La Frontera, S. Francisco, Spinters/ Aunt Lute, 1988.

BALDWIN, J., Evidence of Things Not Seen, New York, Henry Holt \& Co, 1985.

BHABHA, H. K., O Local da Cultura, Belo Horizonte, Editora UFMG, 1998.

CABRAL, A., Documentário, Lisboa, Cotovia, 2008.

CARDOSO, D. M. , O Retorno, 2a ed. Lisboa: Edições Tinta -da -China, 2011.

COSTA, C. de L., O sujeito no feminismo: revisitando os debates, in Cadernos Pagu, 2002, p. 59-90.

COSTA, C. de L., Feminismo e tradução: Entre o colonialismo acadêmico e a diferença pós-colonial, in ANPOCS, $2004 \mathrm{http} / / /$ docplayer.com.br/17366525-Xxviii-encontro-anual-anpocs2004.html.

FANON, F., The Wretched of the Earth, New York, Grove Press, 1968. 
FEMENÍAS, M. L., Afirmación identitaria, localización y feminismo mestizo. In: Feminismos de París a La Plata, Buenos Aires, Catálogos, 2006. p. 97-125.

FIGUEIREDO, I., Caderno de Memórias Coloniais, Alfragide, Editorial Caminho, 2015.

FOUCAULT, M., Microfísica do poder, 24a ed., Rio de Janeiro, Graal, 2007.

GILROY, P., Entre campos, nações, cultura e o fascínio da raça, São Paulo, Annablume, 2007.

MOHANTY, S.P. Literary Theory and the Claims of History, Chapter I, The epistemic Status of Cultural Identity, On beloved and the Postcolonial Condition, Spring, 1993.

PAREDES, M., O Tibete de África, Porto, Âmbar, 2006.

PAREDES, M., Combater Duas Vezes, Mulheres na Luta Armada em Angola, Vila do Conde, Verso da História, 2015.

RIBEIRO, R., O retorno, uma cartografia emocional ainda por escrever. in Descolonização, o Drama da Integração, vol. 8, Vila do Conde, Verso da História, 2015, p. 106-111.

RICHARD, N., Experiência e Representação O Feminino, o Latino-Americano, Intervenções críticas, Arte, cultura, género e política, Belo Horizonte, UFMG, 2002.

SHOHAT, E. (2004) Estudos de Área, Estudos de Gênero e as cartografias do conhecimento, Poéticas e Politicas feministas, Ilha de Santa Catarina, Editora Mulheres, 2004. 